\section{Heredity: Science and Society: On the Possibilities and Limits of Genetic Testing and Gene Therapy}

Committee of the Health Council of The Netherlands, 196 pages, The Hague, Dfl 165, The Health Council of The Netherlands, 1989

This comprehensive report was prepared by a committee comprising four geneticists, two specialists in health law plus one other lawyer, two ethicists, and experts in philosophy, social medicine, medical information and toxicology. Thus, the feet of the geneticists must surely have been kept firmly on the ground as the uses of the new developments in genetic knowledge as applied to medicine were discussed. It is indeed a very balanced report, overall encouraging the application of new techniques but judiciously warning about possible danger areas. Since its submission, The Netherlands' government has formally endorsed many of its recommendations, by using it as a basis for a policy document.

The committee examined genetic diagnosis and counselling, genetic registers, cell banks, population screening, pre-implantation testing, gene therapy, and genetic testing outside the health-care system with special reference to insurance and employment. It considered associated issues, the social, ethical and legal implications and the consequences for individuals and for society as a whole and for groups within it.

Hitherto, advances in genetics have principally been influential in the realm of reproduction. This has been through counselling of couples who have had a child, or have a close family member affected by a genetic disease, to advise on risks in a future pregnancy, and, with increasing sophistication and accuracy, prenatal diagnosis of any conceptus which may arise. Now, we are on the threshold, not only of enhancing this area with preimplantation diagnosis, but also of extending genetic diagnosis and risk assessment to all individuals, for genetic disorders they might develop in later life, such as cardiovascular disease. With the pace of genetic research increasing as plans for mapping the whole human genome materialise, it may not be long before we have genetic markers for many of the common diseases of advancing years, and it will be possible to predict, even in utero, whether an individual is at risk of developing, for example, diabetes mellitus, high blood pressure, ischaemic heart disease or duodenal ulcer, and probably some types of cancer too. The advantages of this are that it will lend itself to preventive medicine, for many of these disorders are not purely genetic: environmental factors are also necessary for their expression, and if these can be specifically circumvented, then much of such disease could be avoided. But not all late onset genetic disease can be prevented, or even treated, and it is questionable whether there are any benefits in knowing in advance that one is to develop these. The report discourages mass genetic screening per $s e$ as a goal. Most welcome too is its recommendation that the use of genetic testing by insurance companies for prospective clients, and also the disclosure of prior genetic information, should be banned. Similarly, it rejects genetic testing in the selection process for employment, save in certain circumstances when it is in the interests of a third party or to protect the health of the individual. There is a good coverage of the whole matter of privacy of information, for it is important in other contexts too. Basic information including genetic data about patients is kept in computer data banks, genetic registers form an essential part of genetic services and of research, and genetic information about a person can have important implications for other family members. It is generally agreed that limits must be put on access to this information to preserve confidentiality, but the report also recommends that the use of any genetic data should be restricted to the purposes for which it was collected, and asks for monitoring committees to be set up to ensure compliance in this matter.

The report is well argued, informative, all-embracing and a fair appraisal of the prospects for the future - hope for, and acceptance of, the benefits which might accrue, while offering realistic safeguards and prohibitions. Dutch society has been well served by this committee: their report deserves to be widely read.

MARY J SELLER, Reader in Developmental Genetics, Paediatric Research Unit, Division of Medical and Molecular Genetics, 7th Floor, Guy's Hospital Tower, London Bridge, London SEI 9RT.

\section{AIDS a Moral Issue - Ethical, Legal and Social Aspects}

Edited by Brenda Almond, 184 pages, Hampshire, $£ 40.00 \mathrm{hb}, £ 14.99 \mathrm{pb}$, Macmillan Press Ltd, 1990

AIDS is a frightening condition, killing large numbers of young people; it has spread into all groups within the community and there are no clear means of prevention. Partly because AIDS is sexually transmitted it has 